\title{
Study on the Obstacles in Using of College English Excellent Courses Based on the Learner's Perspective*
}

\author{
Yuman Lin \\ Department of education \\ Shaoguan University \\ Shaoguan, China \\ gd_lym@163.com
}

\begin{abstract}
At present, the researches on the College English Excellent courses are mostly from the perspective of curriculum developers or teachers, but not from the perspective of learners. However, The study found that the factors which affect the learners' use of the course include: (1) the design of curriculum resources has not considered the students' English foundation and interest; (2) learners' learning motivation is different, and the internal motivation is low;(3)learners' acceptance degree is different;(4) learners' information literacy is uneven. The construction of quality resources should be started from the perspective of learners, and improve the effectiveness of its teaching application in the future.
\end{abstract}

Keywords-college English excellent courses; learner's perspective; learning motivation; information literacy

\section{RESEARCH BACKGROUND AND SIGNIFICANCE}

The program of National Excellent Courses was started by The Ministry of Education since April 2003.The construction of Excellent Courses promotes the university to establish the information learning environment, and gradually improves the support service standard; provide high quality support services for students' individualized learning. It plays a significant role in improving the level of school classroom teaching, promoting higher education information technology and curriculum integration. Along with the continuous development of related research, the research found that there are some problems in the construction of Excellent Courses: (1)paying more attention to declaring but less to construction, emphasizing the quantity and neglecting the quality; (2)social awareness is not enough; (3)benefits are not obvious; (4)lack of effective management mechanism.

National Excellent Courses is a service to the learners, but at present, the quality course satisfaction of the learners is not high. Finding out the cause of this situation is important to improve the construction of Excellent Courses platform.

\section{RESEARCH STATUS}

Although there are some research on the development of College English Excellent Course, most of them are the research on the construction and application of College English courses, and there is a small amount of barriers to the use of College English courses. And most of the research on College
English Excellent Course is carried out in the perspective of developers and teachers.

The researches mainly summarize the present situation and existing problems of the construction of College English Excellent Courses, and discuss how to build a good college English Excellent course, and explore how to use college English Excellent courses to promote English learning.

A. The Present Situation and Problems of College English Excellent Courses

- Zhao Sufang, Dang Xiaoling and Zhang Zhi had researched College English Excellent Courses of 15 universities. Besides, the statistics and analysis were carried out roundly. The survey showed that College English Excellent Courses existed some problems, such as quiet feature of the construction, serious shared issue, negative interactive module construction, defective daily management and content construction of National Excellent Course Website and so on.

- Considering 54 English language class in the National Excellent Courses as the research object, which are selected from 2003 to 2008, Zong yun analyzed in detail from the overall situation, curriculum module construction, operation of the three aspects of the construction of the website. The research showed that the overall construction quality of the website needed to be improved; the degree of curriculum resources sharing was not enough.

- Wang Runxiao, Xu Xiaoyu analyzed College English Excellent Course of nine universities, which were selected from 2003 to 2007, and summarized several points of experience and characteristics. The study found that school curriculum content of College English courses, teachers, teaching materials, teaching methods and teaching management of comprehensive construction, had been formed with Excellent teaching contents, modern teaching methods and means, scientific and reasonable teacher echelon construction design, three-dimensional teaching quality system, strict teaching management measures of curriculum system. 
B. Construction and Design of College English Excellent Courses

- $\quad$ Liu Sheng and Fang Rui considered building a network teaching platform is an important part of College English Excellent courses, it could set up the new mode of learning language. But actually English teaching platform was limited, the aspects of teaching content and website design both had some problems. So it is necessary to innovate course content, strengthen the construction of College English courses teaching platform, which is constructed with student-centered.

- $\quad$ Liu Zengcai and Wang Ming considered that dynamic web technology was the important condition of success of Excellent courses, so the research and analysis of the characteristics of the College English Excellent courses was carried on in detail, which included teaching, online learning tools, animation appreciation and online examination and so on. And the study showed that the dynamic web technology could meet the needs of content representation of the College English Excellent courses.

- Liu Qiang and $\mathrm{Hu}$ Xuefei mainly introduced the system structure and main function modules of College English Excellent Courses. Otherwise, it introduced the key technology adopted in the system implementation. The research showed that the construction of College English Excellent Courses achieved the high quality of network teaching resources sharing, and stimulated the enthusiasm of students' autonomous learning, improved the efficiency of language learning.

- Xu Xiaoyu, Zhao Xueai and Wang Runxiao constructed College English Excellent Course website which included the autonomous learning network course, the electronic course-ware resource and streaming media resource library.

\section{Using the College English Excellent Courses for Assisting} English Learning

- The research of $\mathrm{Wu}$ Lin and Jia Qin showed that learners who studied in the circumstance of College English Excellent Courses, could enhance their interest in learning, strength their learning strategy and increase the opportunity of cooperation study with interaction. The resource of College English Excellent Courses is especially rich, which promote their initiative and enthusiasm in learning English adequately. Learners can select the way to study automatically and make their own learning steps and plans, also can obtain and handle the information, which training their knowledge and the ability of learning vastly. What's more, the online exchange modular in the internet is good to set up the dynamic learning model "independent study and coach" and expand the traditional model of English course infinitely.

- Chen Mei considered that the most urgent problem to be solved is to improve the quality of college English teaching. By using modern multimedia technology which changed the traditional teaching mode of College
English, teachers and students could make full use of network resources for teaching and autonomous learning. It becomes the important way to improve the quality of College English teaching. College English Excellent Courses play an important role in assisting students in promoting learning efficiency from three respects, including improving autonomous learning environment, extending classroom teaching and promoting the interaction between teachers and students and the students' cooperation.

- Lin Mingjin and Huang Yuanzhen summarized the theory and practice achievements of the construction College English Excellent Courses of Fujian Normal University. And the three major characteristics of Fujian normal university College English Excellent Course were introduced. It introduced how to build a network platform to promote language input by using the autonomous learning strategy, collaborative learning strategy, interactive learning and other teaching strategy.

- Liu Xuliang considered students use the Internet for autonomous learning, which make the teaching material from the textbook extended to comprehensive network space, and enrich the connotation and extension of teaching. It requires students to learn to master modern technology, to develop their own knowledge, and to carry out autonomous learning ability, and it can improve the overall quality of students.

- The research of The MingXia which is based on domestic and foreign research on the theory of independent learning, and based on the practice of College English teaching reform in Hubei University of Economics, analyzed the present situation and necessity of autonomous learning monitoring and control. And the contents of autonomous learning monitoring system, such as autonomous learning, monitoring and controlling, monitoring and controlling, are discussed, the construction of monitoring system of College English Autonomous Learning under the network environment is proposed.

\section{FACTORS AFFECTING LEARNERS' USE OF COLLEGE ENGLISH EXCELLENT COURSES}

The research shows that the design of the existing College English Excellent Courses and the resources of it are not fully in line with the needs of the learners. The students' understanding of the Excellent Course is low, the usage rate of it is low, and the satisfaction of it is not high also. For students, there are some obstacles in using the College English Excellent Courses.

\section{A. The design of curriculum resources has not considered the students' English foundation and interest}

Because of the students' English learning foundation and interest, teachers' teaching methods and teaching progress are not the same. College English Excellent Courses did not take into account the differences of students, and not design the corresponding resources for different students. All the students 
are learning and using the same resources, which caused the use of obstacles to students.

The teaching activities of Excellent Courses can be design in different levels, according to different levels of English learners. So different English learners can choose according to their own actual situation of teaching activities.

The resource of the course platform has lagged behind, and there are a lot of advertisements in the job submission area. For making the work area to play a good role, the management of the course platform should do well in the work of management and improve the platform construction.

The teaching resources of the Excellent Courses are mainly provided by the learning materials, lack of appropriate expansion resources and English learning methods and skills. It should enrich the curriculum resources, better meet the needs of learners.

\section{B. Learners' learning motivation is different, and their internal motivation is low}

There are many factors that affect the use of College English Excellent Courses. Learning motivation is the main factor for learners. There are also big differences in the learning motivation of different learners, and internal motivation is lower entirely, especially those with low interest in learning English learners. For most learners, it's more boring to learn foreign language. If College English Excellent Courses cannot increase learners' interest in learning English, so it is a kind of form.

To increase the learner's internal motivation, it needs to combine classroom and extracurricular activities, stimulate the learner's learning interest and knowledge. Various competitions can be held, for example, Writing and reading competitions, English speech contest, English speech contest, English drama and chorus competition. Competition can be divided into three levels according to different English teaching classes; it will affect the enthusiasm of students in different level. In the classroom, teachers should pay attention to mobilize the enthusiasm of learners, to pay attention to the individual differences of learners.

The evaluation method of the quality course is the way of online question answering, which depends on the platform, which has time and space limitation for learners to learn English. College English Excellent Courses can be interacted with QQ, micro-blog and other mobile communication mode. The learners usually participate in the Excellent courses will be a reference to the results. In order to stimulate the learning interest, it should pay attention to the students' usual participation.

\section{Learners' acceptance degree of College English Excellent Courses is different}

Excellent courses learning is only one form of online learning because the learners are used to use the Search Engine to search the answers. Their ability of searching message and resources is relatively good, so they are tend to deal with learning problems by using the Search Engine to search the resources they need. College English Excellent Courses can not meet the requirement of learners, and learners can not search the resources they need immediately in the advances courses.

Teachers play the role of the model. Teachers often access to Excellent Courses, the learners will be affected to a certain extent will increase the frequency of access to Excellent Courses. Teachers want students to be able to participate in the study of Excellent Courses, first of all, teachers should be involved, but not in the identity of the outsider teaching.

Curriculum platform provides quality resources, but the learners do not know how to use, this is a waste of resources. In order to enable the learners to make good use of the resources of the course platform, first of all, we should let the learners learn to find the resources they need. In order to solve this problem, English teachers in the classroom can show students how to find some of the more common resources.

The help guide can be set up to the website of Excellent Courses, also build feedback areas, in which students can submit some of the problems encountered in the use of the platform, the curriculum management or builders can reply it. The students can also give some suggestions on the course construction to improve the construction process.

\section{Learners' information literacy is uneven}

Learners' abilities of changing formats and chatting online are not good as searching information and resources, updating files, downloading resources and using media players. There is a big difference between different individuals. This is related to learners' information literacy, their interest in computer operation and their professional direction. Influence of requirements of professional courses, learns which should learn large computer operations, will have more time to study the relevant operation, enhance their information literacy. If some of the learners' subject is less about information, their information literacy is poor.

As college students should have the basic information literacy, the cultivation of information literacy mainly depends on their own efforts, also subject to the impact of the course requirements. The learners themselves can improve their learning by the information technology curriculum and professional courses. The cultivation of information literacy, such as basic, common operational skills, can be strengthening in computer courses, which provide technical support for the use of resources and functions of the platform. The students' information literacy can also be improved through the use of some of the activities of the competition.

\section{CONCLUSION}

At present, the research on the College English Excellent courses mainly includes :(1) the present situation and problems of the construction of College English course; (2) the construction and design of the College English Excellent courses.(3) using the College English Excellent courses for assisting English learning. These studies are mostly from the perspective of curriculum developers or teachers, but not from the perspective of learners.

However, The study found that the factors which affect the learners' use of the course include: (1) the design of curriculum resources has not considered the students' English foundation 
and interest; (2) learners' learning motivation is different, and the internal motivation is low;(3)learners' acceptance degree is different;(4) learners' information literacy is uneven.

The construction of quality resources should be started from the perspective of learners, and improve the effectiveness of its teaching application in the future.

\section{ACKNOWLEDGMENT}

This paper supported by Foundation of Guangdong Education Department(Grant No. 2013WYM 0076) and Foundation of Guangdong Philosophy and Social Project(Grant No.GD13CJY07) .

\section{REFERENCES}

[1] Zhao Sufang, Dang Xiaoling and Zhang Zhi, "Analysis of the current situation of the construction of the national college English advance courses," Journal of Southwest Agricultural University(Social Sciences Edition, vol. 8,No.4, pp. 136-138, Aug. 2010. (references)

[2] Zong Yun, "Design of state benchmark courses: an analysis of English courses," Distance Education in China, pp. 45-49, Oct. 2009.

[3] Xu Xiaoyu,Wang Runxiao, "Construction of the national excellent course "college English"," Research in Higher Education of Engineering, pp. 145-148, Jan. 2008.

[4] Liu Sheng, Fang Ruifang, "Construction and thinking of the network of the excellent Course "Basic English", Journal of Southwest
Agricultural University(Social Sciences Edition), vol.10,No.6, pp. 125126, Aug. 2012.

[5] Liu Zengcai,Wang Min, "Design of English excellent course website based on dynamic web techniques," Journal of Hubei Polytechnic, vol.11,No.2, pp.97-99, Jun. 2008.

[6] Liu Qiang,Hu Xuefei, "Design and construction of excellent course website of "advanced English" course," China Education Info, pp.67-69, Mar. 2008.

[7] Xu Xiaoyun,Wang runxiao,Zhao Xueai, "Construction and thinking of the website of national excellent course "college English"," China Educational Technology, pp.57-59, Jan. 2008.

[8] Wu Lin,Jia Qin, "Improving students' autonomous learning ability through network-based English great courses," Journal of Wuhan Institute of Technology, vol.31,No.10, pp.80-83,Oct. 2009.

[9] Chen Mei, "Discussion on the construction of higher vocational English courses to promote students' autonomous learning ability," Science and Technology Innovation Herald, No.27, pp.167, Sept. 2010.

[10] He Mingxia, "The monitoring of college English self-regulated learning based on network environment," Shanghai International Studies University, 2012

[11] Liu Xuliang, "How to make use of the Internet to study English independently," Science Information, No.14, pp.157-158, May. 2007

[12] Lin Mingjin,Huang Yuanzhen,"Characteristics of "virtual" and "real", multilateral interaction, and static-dynamic integration -- The theoretical support of the brand-new teaching system and practical teaching achievements of the college English," Journal of Fujian Agriculture and Forestry University,vol.13, No.2, pp.97-102, Mar. 2010 